\title{
Discovery of new fluorescent thiazole-pyrazoline derivatives as autophagy inducers by inhibiting mTOR activity in A549 human lung cancer cells
}

\author{
ZhaoMin Lin', ZhaoYang Wang ${ }^{2}$, XueWen Zhou ${ }^{3}$, Ming Zhang ${ }^{1}$, DongFang Gao', Lu Zhang ${ }^{1}$, Peng Wang ${ }^{1}$, \\ Yuan Chen', YuXing Lin', BaoXiang Zhao ${ }^{3}$, JunYing Miao ${ }^{2}$ and Feng Kong ${ }^{1,4}$
}

\begin{abstract}
A series of fluorescent thiazole-pyrazoline derivatives was synthesized and their structures were characterized by ${ }^{1} \mathrm{H}$ NMR, ${ }^{13} \mathrm{C}$ NMR, and HRMS. Biological evaluation demonstrated that these compounds could effectively inhibit the growth of human non-small cell lung cancer (NSCLC) A549 cells in a dose- and time-dependent manner in vitro and inhibit tumor growth in vivo. The structure-activity relationship (SAR) of the compounds was analyzed. Further mechanism research revealed they could induce autophagy and cell cycle arrest while had no influence on cell necrosis. Compound $\mathbf{5 e}$ inhibited the activity of mTOR via FKBP12, which could be reversed by 3BDO, an mTOR activator and autophagy inhibitor. Compound $\mathbf{5 e}$ inhibited growth, promoted autophagy of A549 cells in vivo. Moreover, compound $\mathbf{5 e}$ showed good selectivity with no influence on normal vascular endothelial cell growth and the normal chick embryo chorioallantoic membrane (CAM) capillary formation. Therefore, our research provides potential lead compounds for the development of new anticancer drugs against human lung cancer.
\end{abstract}

\section{Introduction}

Cancer is still a major global health concern and a leading cause of death all over the world. It is shown that lung cancer remains the highest death rate in all cancer deaths both in developed and developing countries ${ }^{1}$. Over the past decades, much attention has been paid to the discovery of effective method to overcome cancer thoroughly. Despite more and more anticancer therapies were developed, chemotherapy is still one of the most common cancer therapies to prolong the lifespan of cancer patients $^{2,3}$. However, due to side effect and drug resistance, it is an urgent issue to develop novel, selective anticancer agents.

\footnotetext{
Correspondence: Feng Kong (kongfeng@sdu.edu.cn)

${ }^{1}$ Institute of Medical Science, The Second Hospital of Shandong University, Jinan 250033, PR China

${ }^{2}$ Shandong Provincial Key Laboratory of Animal Cells and Developmental Biology, School of Life Science, Shandong University, Jinan 250100, PR China Full list of author information is available at the end of the article Edited by M Hamasaki
}

Nevertheless, studying the distribution and targets of anticancer compounds in living cells poses a great challenge for researchers and great help to improve the activity and selectivity. Fluorescigenic small molecules provide a huge boost for determining their location and targets in living cells. Fluorescent compounds have been used as powerful detection tools in cell biology. Currently, due to the nature of high quantum yield and readily synthetic process, some pyrazoline derivatives have been synthesized and used in fluorescence probes, for orientation $^{4}$, detecting cation ${ }^{5-8}$, hydrazine ${ }^{9,10}$, thiols ${ }^{11-13}$, and $\mathrm{DNA}^{14}$. Moreover, their biological roles have been studied in insecticidal function ${ }^{15-17}$, human monoamine oxidase activity inhibition ${ }^{18,19}$, anti-inflammation ${ }^{20-22}$, antimicrobial $^{23,24}$, analgesia ${ }^{25}$. In addition, pyrazoline derivatives could inhibit the proliferation of cancer cells with satisfactory activity ${ }^{26,27}$. However, the anticancer mechanism was little delineated.

Autophagy, an important process in eukaryotes through which useless organelles were delivered to lysosomes for

\section{(c) The Author(s) 2020}

(c) (i) Open Access This article is licensed under a Creative Commons Attribution 4.0 International License, which permits use, sharing, adaptation, distribution and reproduction cc) in any medium or format, as long as you give appropriate credit to the original author(s) and the source, provide a link to the Creative Commons license, and indicate if changes were made. The images or other third party material in this article are included in the article's Creative Commons license, unless indicated otherwise in a credit line to the material. If material is not included in the article's Creative Commons license and your intended use is not permitted by statutory regulation or exceeds the permitted use, you will need to obtain permission directly from the copyright holder. To view a copy of this license, visit http://creativecommons.org/licenses/by/4.0/. 
degradation and reuse, plays double-edged roles in tumor initiation and progression depending on different cell types and specific stages of tumor progression ${ }^{28,29}$. On the one hand, autophagy deficiency has a positive effect on malignant transformation, indicating autophagy as a tumor suppressor mechanism ${ }^{30,31}$. On the other hand, excessive autophagy could contribute to cell death in certain cancer cell types which maintained the cellular functions by triggering autophagy ${ }^{32,33}$. Considering the dual nature of autophagy in tumorigenesis and progression, more modulators of autophagy may provide a powerful tool for cancer therapy.

Mechanistic target of rapamycin (mTOR [serine/ threonine kinase]/FK506-binding protein 12-rapamycin associated protein 1), regulates the maintenance of cell homeostasis, including cell growth, autophagy, and cytoskeletal organization $^{34,35}$. The dysregulated activity of mTOR involved in several human disorders, including cancers, such as lung cancer, breast cancer, and others ${ }^{36}$. Due to the key role of proliferation in numerous malignant cell types, there were many potential applications in the therapy of various solid tumors and hematological malignancies by targeting the mTOR pathway ${ }^{37,38}$. However, the expectations of more effective and less toxic treatment with mTOR inhibitors have not realized.

In a continuation of an ongoing program aiming at finding novel fluorescent small molecules with anticancer activity $^{39-41}$, a series of thiazole-pyrazoline derivatives were synthesized and their properties in A549 cells were evaluated. In this work, deep insights into the antineoplastic activity and mechanism of pyrazoline derivatives were gained to provide a basis for the rational and targetable design of fluorescent anticancer drug for clinical application.

\section{Materials and methods \\ Reagents and apparatus}

All reagents were of analytical grade or chemically pure. Thin-layer chromatography (TLC) was performed on silica gel $60 \mathrm{~F}_{254}$ plates (Merck KGaA) and column chromatography was conducted over silica gel (mesh 200-300). ${ }^{1} \mathrm{H}$ NMR spectra were recorded on a Bruker Avance $400(400 \mathrm{MHz})$ spectrometer or Bruker Avance $300(300 \mathrm{MHz})$ spectrometer, using DMSO-d6 as solvent and tetramethylsilane as an internal standard. Melting points were determined on an XD-4 digital micro melting point apparatus. IR spectra were recorded with an IR spectrophotometer Avtar 370 FT-IR (Termo Nicolet). MS spectra were recorded on a Trace DSQ mass spectrograph. Unless otherwise stated, all reagents were purchased from J\&K, Sinopharm Chemical Reagent Co. and Kermel and used without further purification. Twicedistilled water was used throughout all experiments. Rapamycin was from Calbiochem (Darmstadt, Germany).
Chloroquine (CQ) and Bafilomycin-A1 (Baf-A1) were purchased from Sigma-Aldrich (St. Louis, MO, USA).

\section{Preparation of chalcone compounds (3)}

In a flask, compound $\mathbf{1}(10 \mathrm{mmol})$ was dissolved in ethanol $(10 \mathrm{ml})$, and sodium hydroxide solution in water $(8 \mathrm{ml}, 2.5 \mathrm{M})$ was added. Then compound 2 dissolved in ethanol $(10 \mathrm{ml})$ was added to the above mixture. After reaction completed (by TLC monitoring), yellow precipitate was filtered, then the solid was washed with water to make $\mathrm{pH}=7$. The yellow product was dried by infrared lamp to give compound 3 in more than $80 \%$ yield.

\section{Preparation of 3,5-diaryl-4,5-dihydro-1H-pyrazole-1- carbothioamide (4)}

Thiosemicarbazide $(6 \mathrm{mmol})$, sodium hydroxide $(8 \mathrm{mmol})$, compound 3 and ethanol $(30 \mathrm{ml})$ were added into round-bottom flask. The reaction mixture was refluxed for $3-8 \mathrm{~h}$, it was monitored by TLC until completion. The mixture was cooled to room temperature. Precipitate was filtered, and washed three times with water and ethanol. After dried with infrared lamp, corresponding product $\mathbf{4}$ was obtained.

\section{Preparation of compound 5}

Compound 4 (1 mmol) was added into ethanol $(25 \mathrm{ml})$, then 2-bromo-1-(pyridin-4-yl)ethanone $(1 \mathrm{mmol})$ was added into the mixture. The reaction mixture was refluxed for 4-9 h (monitored by TLC until completion). The mixture was cooled to room temperature and filtered. The solid was washed with ethanol two times. The solid was dissolved in dichloromethane. The mixture was washed with saturated $\mathrm{NaHCO}_{3}$, followed by wash with saturated brine. Organic phase was dried over magnesium sulfate. After desiccant was removed by suction filter, organic phase was concentrated under reduced pressure to give the target products 5 . The spectroscopy data of compounds $\mathbf{5 a}-\mathbf{5 j}$ are loaded in the Supplementary file.

\section{Antibodies}

Antibody for Light chain 3 beta (LC3B) (2775 S), EIF4EBP1 (9452), p-EIF4EBP1 (9459), RPS6KB1 (9202), p-RPS6KB1 (9205), and p-mTOR (2971) were purchased from CST. Antibody for $\beta$-actin (sc-47778), mTOR (sc8319), FKBP12, and horseradish peroxidase-conjugated secondary antibodies were bought from Santa Cruz. Secondary antibodies for immunofluorescence were donkey anti-rabbit IgG Alexa Fluor-488 (A10040), which was purchased from life technology.

\section{Cell culture}

All the cells utilized in the experiment were purchased from the Cell Culture Bank of the Chinese Academy of Sciences (http://www.cellbank.org.cn/). Human lung 
cancer cell line A549 and H460, human liver carcinoma cell line HepG-2, human hormone-independent prostate carcinoma cell line PC3, human kidney clear cell adenocarcinoma cell line 786-O, human breast carcinoma cell line 4T1, and human renal tubular epithelial cell HK-2 were cultured in RPMI-1640 medium with $10 \%(\mathrm{v} / \mathrm{v})$ bovine calf serum and $80 \mathrm{U} / \mathrm{ml}$ penicillin/streptomycin. Human glioblastoma cells U87 and human embryonic kidney cell 293T were grown in DMEM medium (Gibco, USA) with $10 \% \mathrm{FBS}$, penicillin $(50 \mathrm{U} / \mathrm{ml})$, and streptomycin (50 ug/mL) (Invitrogen, 10378-016). Human umbilical vein endothelial cells (HUVEC) were grown in M199 medium (Gibco, 31100-035) with 10\% (v/v) bovine calf serum and $8.4 \mathrm{IU} / \mathrm{mL}$ FGF2. All cell lines were cultured in a humidified incubator with $5 \% \mathrm{CO}_{2}$ at $37^{\circ} \mathrm{C}$.

\section{Cell morphology}

Morphologic changes of A549 cells treated with compounds at indicated concentration for 12, 24, and $48 \mathrm{~h}$ were examined by inverted phase-contrast microscope (Eclipse TS-100; 21 Nikon, Tokyo).

\section{Cell viability assay}

Cells were seeded onto 96-well plates for $24 \mathrm{~h}$ and then treated with $0.1 \%$ DMSO (v/v, as control), 5-fluorouracil (5-FU, as positive group) or compounds $\mathbf{5 a}-\mathbf{5} \mathbf{j}$ at indicated concentrations $(0.1,1,5,10 \mu \mathrm{M})$ for 24 and $48 \mathrm{~h}$. Cell viability was measured by sulforhodamine B (SRB) assay, in accordance with the previous method ${ }^{42}$. The intensity of light absorption was measured by using a SpectraMAX190 microplate spectrophotometer (GMI Co, USA) at the wavelength of $540 \mathrm{~nm}$. In some experiments, A549 cells were transfected with siRNAs and/or treated with 5e. A549 cells were exposed to autophagy inhibitors CQ $(20 \mathrm{mM})$ and Baf-A1 ( $50 \mathrm{nM})$ for $2 \mathrm{~h}$ before treatment with $5 e$.

\section{Lactate dehydrogenase (LDH) assay}

Cell culture medium was gathered after 24-h treatment with compounds $\mathbf{5 a}-\mathbf{5 j}(10 \mu \mathrm{M})$ or $0.1 \%$ DMSO (as control). LDH assay was conducted by using a LDH kit (Nanjing Jiancheng Co, China), according to the manufacturer's description.

\section{Co-localization imaging of cells}

A549 cells were incubated with 5 e $(1 \mu \mathrm{M})$ for $1 \mathrm{~h}$ at $37^{\circ} \mathrm{C}$. Then, MitoTracker Deep Red $(0.1 \mu \mathrm{M})$, Lyso Sensor Green $(0.3 \mu \mathrm{M})$, and ER Tracker Red $(0.3 \mu \mathrm{M})$ were added and incubated for another $0.5 \mathrm{~h}$ and the confocal fluorescent images were captured.

\section{Western blot analysis}

Total proteins were obtained from A549 by using IP lysis buffer (Shanghai beyotime Co., China) after different treatment. Cells were washed twice with ice-cold phosphate-buffered saline (PBS), then lysed in protein lysis buffer (Shanghai beyotime Co., China). The protein concentration of the cells was measured by the Bradford method. Following separation by SDS-PAGE and transferring to PVDF membrane (Millipore, USA), proteins were incubated with primary antibodies, then incubated with horseradish peroxidase-linked secondary antibodies, and finally probed by using an enhanced chemiluminesence detection kit (Thermo). Actin $\beta$ was used as a loading control. The relative quantity of proteins was analyzed by Image J software and normalized to loading controls.

\section{RNA interference}

A549 cells were transiently transfected with siRNA duplex oligonucleotides targeting LC3B (GenePharmcon, Shanghai, China) using Lipofectamine 2000 (Invitrogen, 11668-019). After 24-h transfection, cell lysates were subjected for the western blot assay and cells were treated with $5 \mathbf{e}$ or vehicle for an additional $24 \mathrm{~h}$. Cell viability was determined as described above. FKBP12 siRNA (sc35678) and scramble RNA (sc-37007) were obtained from Santa Cruz Biotechnology. A549 cells at $50-60 \%$ confluence were transfected with 60-nM siRNA against FKBP25, FKBP12, and scramble siRNA with Lipofectamine 2000 according to the manufacturer's instructions. Then cells were harvested and analyzed by western blot.

\section{Flow cytometric analysis of cell cycle distribution}

Following treated with compounds $\mathbf{5 a}, \mathbf{5 d}, \mathbf{5 e}, \mathbf{5 g}$ and $5 \mathbf{h}(10 \mu \mathrm{M})$ for $48 \mathrm{~h}, \mathrm{~A} 549$ cells were harvested and fixed with $70 \%$ ice-cold ethanol, then stained with $50 \mathrm{mg} / \mathrm{ml}$ propidium iodide containing $10 \mathrm{mg} / \mathrm{ml}$ RNase A at $4{ }^{\circ} \mathrm{C}$ for $10 \mathrm{~min}$. The stained cells were analyzed by using a flow cytometer (ImageStream ${ }^{\mathrm{X}}$ MarkII, Amnis, USA). The cell cycle distribution was analyzed by IDEAS software (Amnis, USA).

\section{Immunofluorescence assay}

Treated cells were fixed in $4 \%$ paraformaldehyde $(\mathrm{w} / \mathrm{v})$ for $30 \mathrm{~min}$ at room temperature and then incubated with normal donkey serum (1:30) for $30 \mathrm{~min}$ and primary antibodies $(1: 100)$ overnight at $4{ }^{\circ} \mathrm{C}$. Cells were washed with PBS times, and then three incubated with secondary antibodies $(1: 200)$ for $1 \mathrm{~h}$ at $37^{\circ} \mathrm{C}$. Fluorescence was detected by laser scanning confocal microscopy Zeiss LSM700 (Germany). Frozen sections of tumors formed on the chick embryo chorioallantoic membrane (CAM) were fixed with cold acetone for $10 \mathrm{~min}$ and blocked with $10 \%$ normal donkey serum (Solarbio, SL050) for $30 \mathrm{~min}$ at room temperature. Then frozen sections of tumors were incubated with primary antibody (1:100; LC3B, Rabbit polyclonal antibody, Santa Cruz Biotechnology) at $4{ }^{\circ} \mathrm{C}$ 

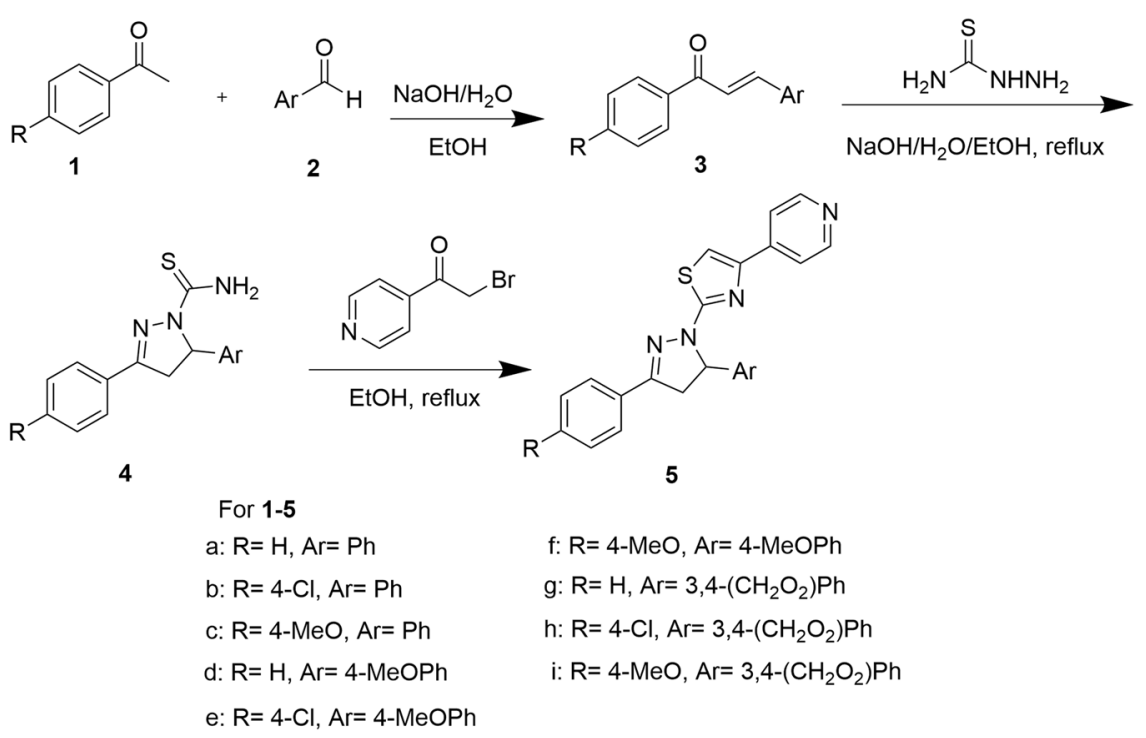

f: $\mathrm{R}=4-\mathrm{MeO}, \mathrm{Ar}=4-\mathrm{MeOPh}$

$\mathrm{g}: \mathrm{R}=\mathrm{H}, \mathrm{Ar}=3,4-\left(\mathrm{CH}_{2} \mathrm{O}_{2}\right) \mathrm{Ph}$

h: $\mathrm{R}=4-\mathrm{Cl}, \mathrm{Ar}=3,4-\left(\mathrm{CH}_{2} \mathrm{O}_{2}\right) \mathrm{Ph}$

i: $\mathrm{R}=4-\mathrm{MeO}, \mathrm{Ar}=3,4-\left(\mathrm{CH}_{2} \mathrm{O}_{2}\right) \mathrm{Ph}$

Scheme $\mathbf{1}$ Synthesis of compounds $\mathbf{5 a - 5 j}$.

overnight and then corresponding secondary antibody $(1: 200)$ at $37^{\circ} \mathrm{C}$ for $1 \mathrm{~h}$. Frozen sections of tumors were washed three times with 0.1-M PBST. DAPI (1:200) was added to stain cell nucleus for $10 \mathrm{~min}$ and then the sections were washed three times with PBS. Fluorescence was detected by confocal fluorescence microscopy Zeiss LSM700 (Germany).

\section{Chick embryo CAM assay}

Fertile chicken eggs (7-9 days old) were used to conduct the CAM assay. An amount of $(1-10) \times 10^{6}$ A549 cells suspended in $20-\mu \mathrm{L}$ RPMI-1640 was engraftment on the CAM. Next, the egg shell was sealed with gas-permeable tape to avoid bacterial infection for another two days. Then, the eggs were treated with PBS (negative control, qod $\times 3)$, the compound $5 e(25$ and $50 \mu \mathrm{M}$, qod $\times 3)$ or 5 $\mathrm{Fu}(50-\mu \mathrm{M}$ positive group, qod $\times 3)$. After fixed by $4 \%$ paraformaldehyde for $30 \mathrm{~min}$, CAMs were separated from the eggs and photographed by a stereomicroscope (Japan).

\section{Angiogenesis assay of CAM in vivo}

Fertilized chicken eggs were incubated with $55 \%$ relative humidity at $37^{\circ} \mathrm{C}$. On embryonic day 7 or 8,5 e (25 and $50 \mu \mathrm{M})$ soaked in the gelatin sponge was applied to the CAM and DMSO as the vehicle control for $48 \mathrm{~h}$. Then, repeated the above operation for three times. At the end of the incubation, after fixed by $4 \%$ paraformaldehyde for $30 \mathrm{~min}$, the CAM zones around the gelatin sponge were photographed and analyzed by using the Image-Pro Plus.

\section{Statistical analyses}

Data were presented as means $\pm \mathrm{SE}$ and analyzed by SPSS software. Pictures were processed with Photoshop software. Mean values were derived from at least three independent experiments. Differences at $p<0.05$ were considered statistically significant.

\section{Results}

\section{Chemistry}

The synthetic route of compounds $\mathbf{5 a - 5 j}$ has been accomplished as shown in Scheme $1^{43}$. An aryl aldehyde (1) reacted with an aryl methyl ketone (2) to give a chalcone (3). The chalcone (3) reacted with thiosemicarbazide to afford 3,5-diaryl-4,5-dihydro-1H-pyrazole-1carbothioamide (4). Compound 4 reacted with 2-bromo1-(pyridin-4-yl)ethanone to produce target products, 2(3,5-diaryl-4,5-dihydro-1H-pyrazol-1-yl)-4-(pyridin-4-yl) thiazole (5).

\section{In vitro antiproliferative activity and structure-activity relationship (SAR) study}

In order to examine the anticancer activity of compounds $\mathbf{5} \mathbf{a}-\mathbf{5 j}$, we firstly observed the morphological changes of A549 cells treated for 12,24 , or $48 \mathrm{~h}$ by a phase-contrast microscope. The data showed obvious morphological changes in A549 cells treated with the compounds $\mathbf{5 a}-\mathbf{5} \mathbf{j}$ in dose- and time-dependent manners (Fig. S1). Compared with control group, the cell density dramatically decreased and cells were elongated or formed triangle and arborization significantly treated for $48 \mathrm{~h} \mathrm{(Fig.} \mathrm{1a,} \mathrm{an} \mathrm{excerpt} \mathrm{of} \mathrm{Fig.} \mathrm{S1).} \mathrm{SRB} \mathrm{assay} \mathrm{was} \mathrm{con-}$ ducted to investigate the effect of these compounds on cell proliferation. The data indicated that these compounds suppressed the growth of A549 cells in a dosedependent manner after treatment with the compounds for 24 and $48 \mathrm{~h}$ (Fig. 1b). The $\mathrm{IC}_{50}(\mu \mathrm{M})$ values of the 
A

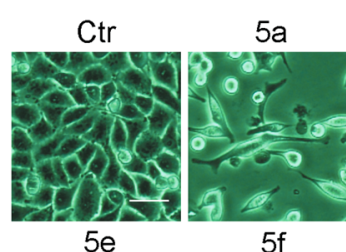

$5 b$

$5 c$

$5 d$
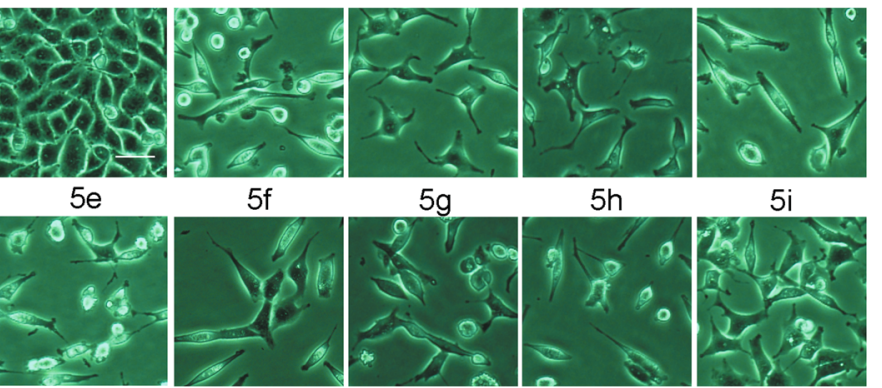

B
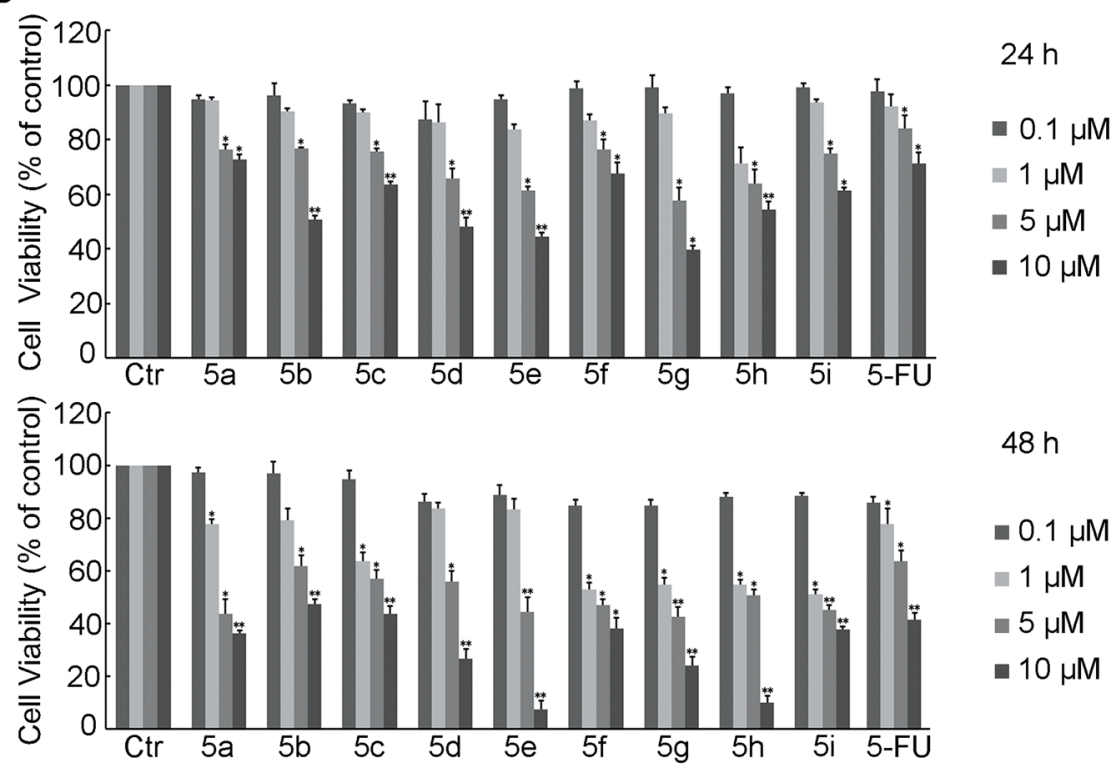

C

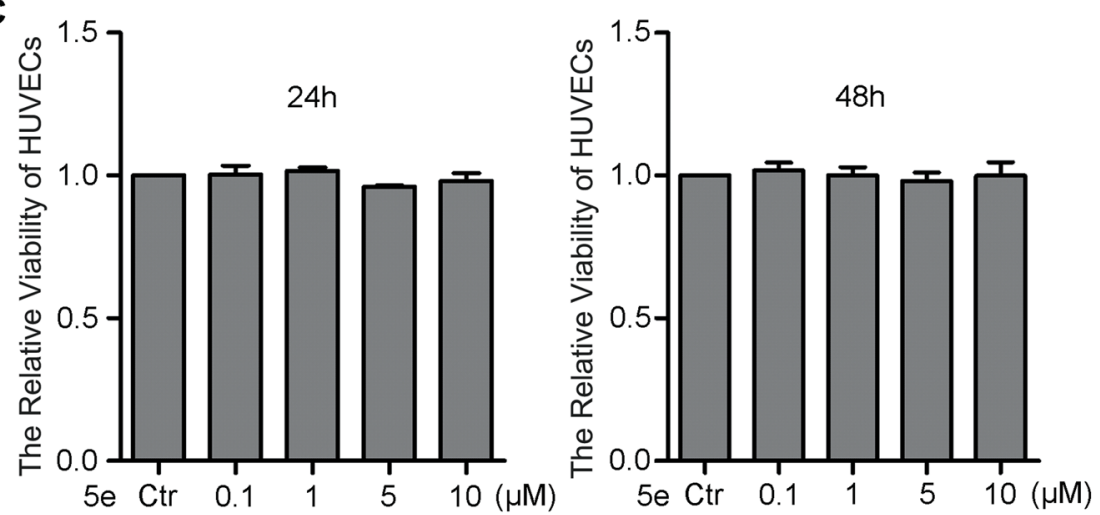

Fig. $\mathbf{1}$ The viability of cells incubated with compounds $\mathbf{5 a - 5 i}$. a Effects of compounds $\mathbf{5 a - 5 i}$ at $10 \mu \mathrm{M}$ on changes in cell morphology for $48 \mathrm{~h}$ $(100 \times)$. These images were re-used from Fig. S1. $\mathbf{b}$ Effects of compounds $\mathbf{5 a}-\mathbf{5 i}$ on cell viability assessed by sulforhodamine B for 24 and $48 \mathrm{~h}$. c The effect of compound $\mathbf{5 e}$ on HUVECs cell viability assessed by sulforhodamine B for 24 and $48 \mathrm{~h}$. Results were presented as mean $\pm S E ; n=3 ;{ }^{*} p<0.05$; ${ }^{* *} p<0.01 . \mathrm{Bar}=20 \mu \mathrm{m}$.

compounds were totally $<10 \mu \mathrm{M}$ (Table 1 ). Our finding demonstrated that all tested derivatives exhibited considerable cell growth inhibition on A549 cells. Furthermore, we explored the inhibitory effect of compound $5 \mathbf{e}$ on human cancer cells lines H460, HepG-2, PC3, 786-O,
4T1, J82, and human nontumorigenic cell lines HK-2 and 293T. As shown in Table S1, compound 5e also exhibited obvious growth inhibiting activity against other cancer cell lines, but did not inhibit the growth of normal cell lines. 5e had no influence on the growth of HUVECs (Fig. 
1c), indicating that this compound showed good selectivity.

Further, based on the above results, the SAR of the compounds was analyzed. The antiproliferative activity of

Table 1 Growth inhibitory properties ( $\mathrm{IC}_{50}, 48 \mathrm{~h}$ ) of compounds $5 a-5 i$ and $5-F U$ in A549 cells. Results are mean \pm SEM.

\begin{tabular}{llll}
\hline Compounds & $\mathrm{IC}_{\mathbf{5 0}}(\boldsymbol{\mu M})$ & Compounds & $\mathrm{IC}_{\mathbf{5 0}}(\boldsymbol{\mu M})$ \\
\hline $\mathbf{5 - F U}$ & $9.4 \pm 0.23$ & $\mathbf{5 e}$ & $2.6 \pm 0.11$ \\
$\mathbf{5 a}$ & $4.4 \pm 0.12$ & $\mathbf{5 f}$ & $2.9 \pm 0.09$ \\
$\mathbf{5 b}$ & $8.7 \pm 0.15$ & $\mathbf{5 g}$ & $1.8 \pm 0.08$ \\
$\mathbf{5 c}$ & $6.0 \pm 0.08$ & $\mathbf{5 h}$ & $1.8 \pm 0.05$ \\
$\mathbf{5 d}$ & $4.7 \pm 0.12$ & $\mathbf{5 i}$ & $2.7 \pm 0.36$ \\
\hline
\end{tabular}

these compounds are mainly affected by aryl group in 5 position of pyrazoline moiety. When substituent $\mathrm{Ar}$ is benzo[d][1,3]dioxol-5-yl (compounds $\mathbf{5 g}-\mathbf{5 i}$ ), the inhibition effect for cell growth is stronger. When Ar is 4methoxyl phenyl (5d-5f), compounds have also a higher growth inhibitory effect. However, in the case of Ar is phenyl, antitumor activity is poorer. Taken together, compounds $5 \mathbf{g}$, $5 \mathbf{h}$ were the most effective compounds in suppressing A549 cell growth.

Continuous proliferation is the hallmark of cancer cells. Because regulation of the cell cycle is critical for cell growth, we investigated the effect of compounds $\mathbf{5}$ on cell cycle progression using flow cytometry. The results showed that compounds $\mathbf{5 a}, \mathbf{5 d}, \mathbf{5 e}, \mathbf{5 g}$, or $\mathbf{5 h}$ effectively arrested the cell cycle at the G1 phase at the concentration of $10 \mu \mathrm{M}$ for $48 \mathrm{~h}$, which were in accordance with the growth inhibitory effect of these compounds. Notably,
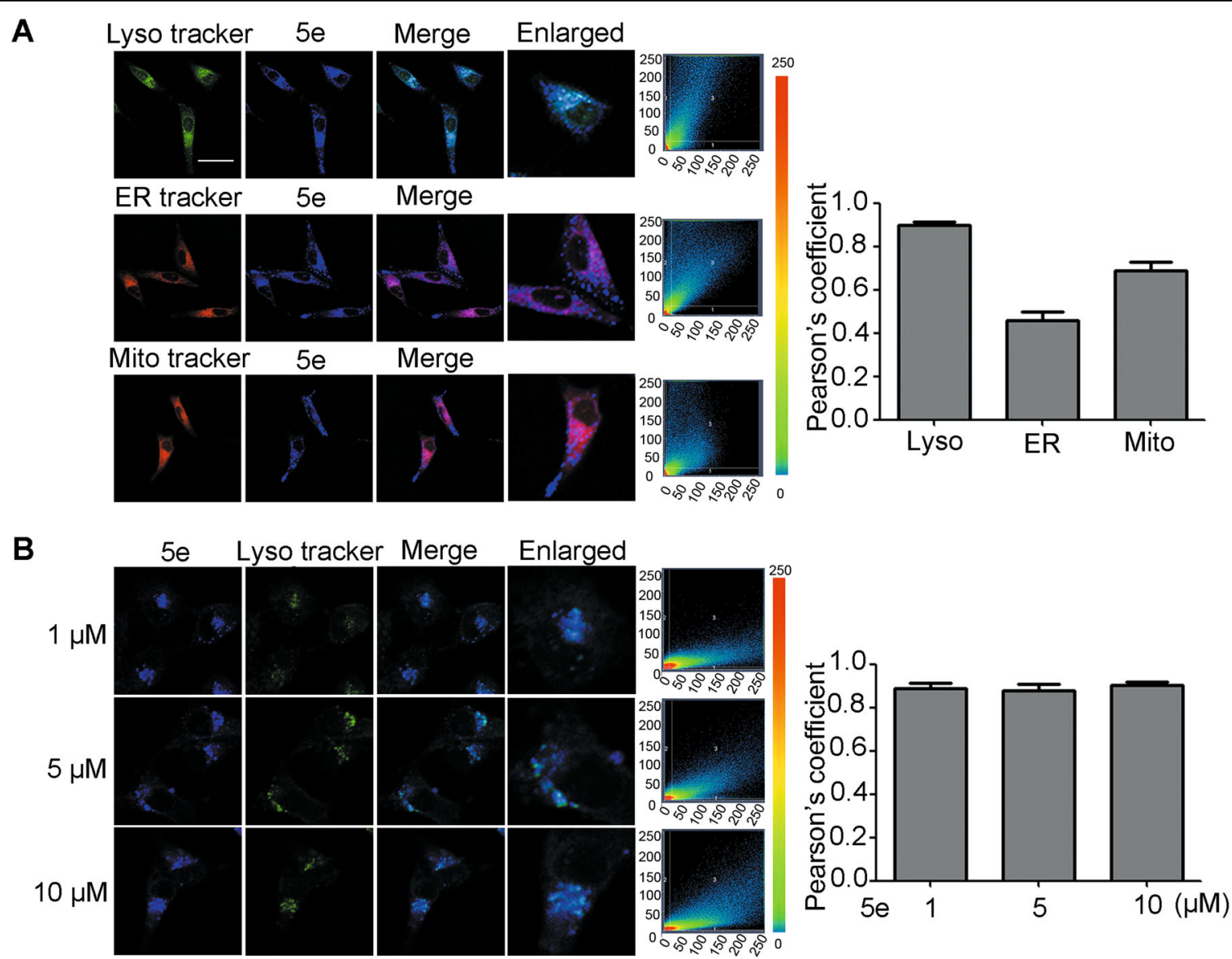

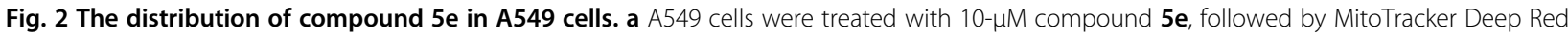
$(0.1 \mu \mathrm{M}, 0.5 \mathrm{~h})$, Lyso Sensor Green $(0.3 \mu \mathrm{M}, 0.5 \mathrm{~h})$, or ER Tracker Red $(0.3 \mu \mathrm{M}, 0.5 \mathrm{~h})$. The average Pearson's coefficient was shown in bar chart. Compound 5e: $\lambda_{\mathrm{ex}}=405 \mathrm{~nm}, \lambda_{\mathrm{em}}=405-490 \mathrm{~nm}$. MitoTracker Deep Red: $\lambda_{\mathrm{ex}}=635 \mathrm{~nm}, \lambda_{\mathrm{em}}=635-700 \mathrm{~nm}$. Lyso Sensor Green: $\lambda_{\mathrm{ex}}=488 \mathrm{~nm}, \lambda_{\mathrm{em}}=$ 488-700 nm. ER Tracker Red: $\lambda_{\mathrm{ex}}=555 \mathrm{~nm}, \lambda_{\mathrm{em}}=555-700 \mathrm{~nm}$. b A549 cells were treated by $1 \mu \mathrm{M}, 5 \mu \mathrm{M}$, or $10 \mu \mathrm{M}$ compound $\mathbf{5 e}$ for $24 \mathrm{~h}$, then, incubated with Lyso Sensor Green $(0.3 \mu \mathrm{M}, 0.5 \mathrm{~h})$. The average Pearson's coefficient was shown in bar chart. Compound $\mathbf{5 e}: \lambda_{\mathrm{ex}}=405 \mathrm{~nm}, \lambda_{\mathrm{em}}=$ 405-490 nm. Lyso Sensor Green: $\lambda_{\mathrm{ex}}=488 \mathrm{~nm}, \lambda_{\mathrm{em}}=488-700 \mathrm{~nm}(200 \times)$. X-axis means mean intensity of compound $\mathbf{5 e}$ and $y$-axis means mean intensity of different trackers. Numbers 1 and 2 mean respective regions and 3 means colocation region. $B a r=10 \mu \mathrm{m}$. 
A
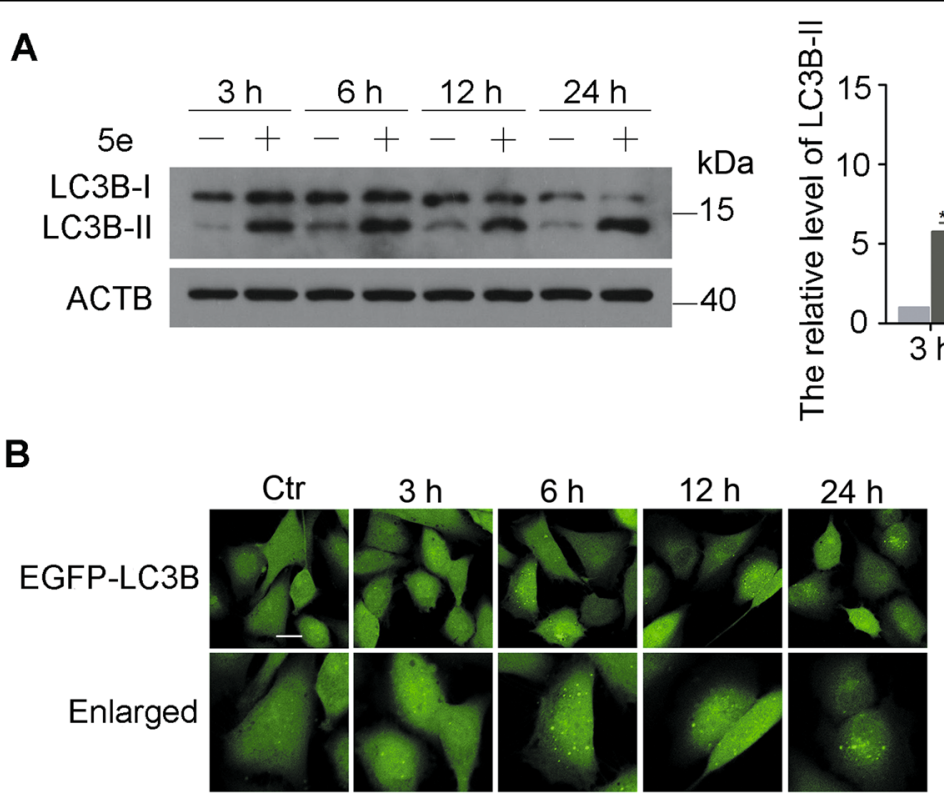

B
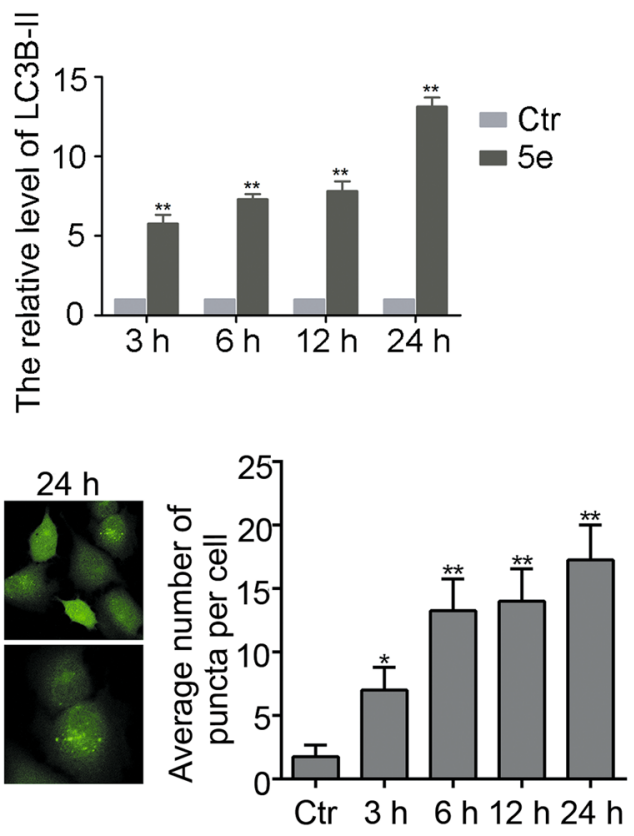

C
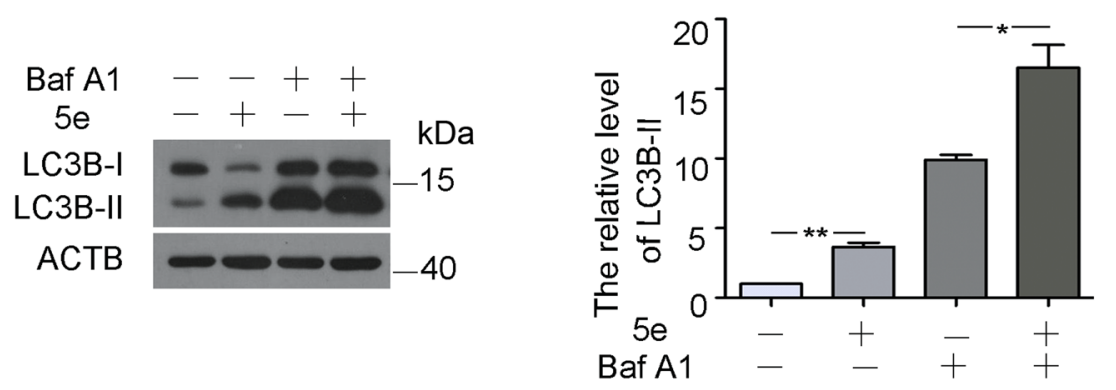

D

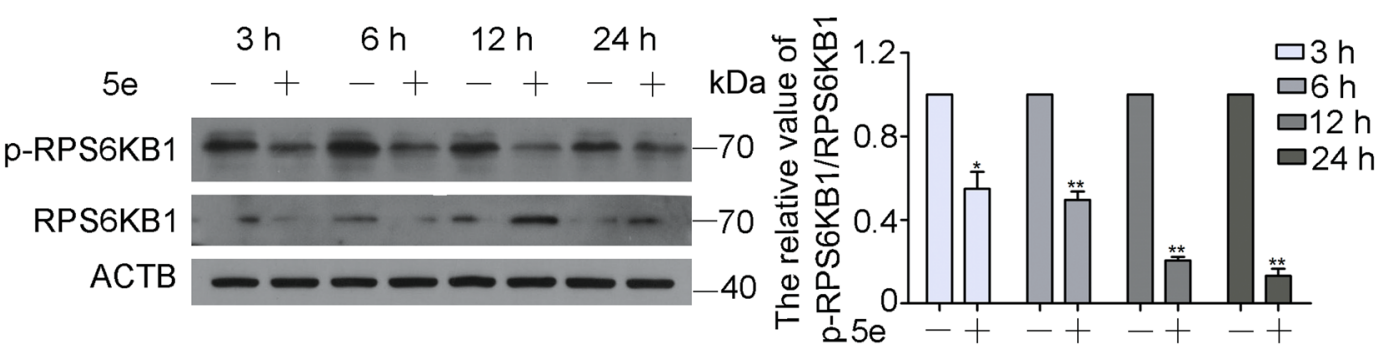

E

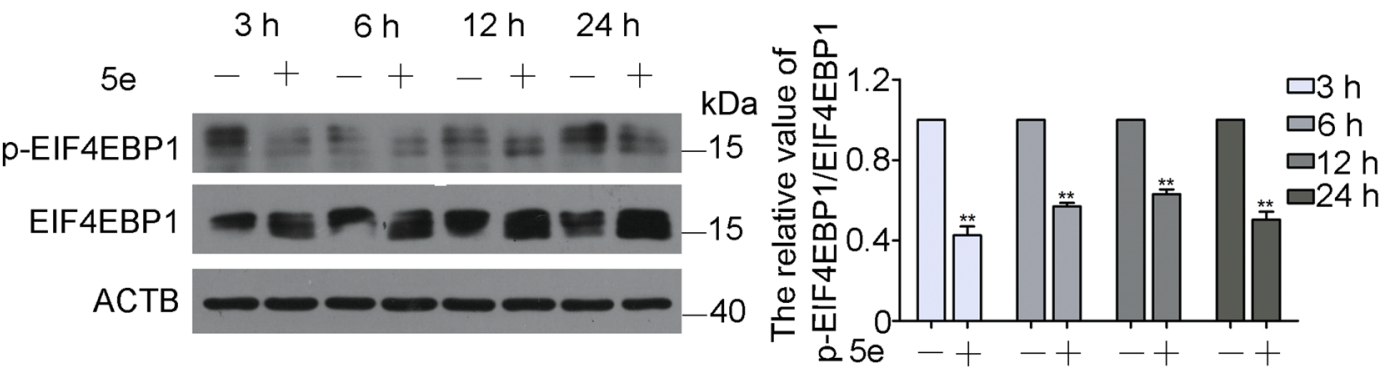

Fig. 3 (See legend on next page.) 
(see figure on previous page)

Fig. 3 Compound 5e induced autophagy in a mTOR-dependent manner. a Western blot analysis of LC3B-I and LC3B-II in A549 cells treated with compound $\mathbf{5 e}$ at $10 \mu \mathrm{M}$ for indicated times and quantification of LC3B-II levels. $\mathbf{b}$ Images of EGFP-LC3B U87 cells were treated with compound $\mathbf{5 e}$ at the concentration of $10 \mu \mathrm{M}$ for 3, 6, 12, and $24 \mathrm{~h}(200 \mathrm{x})$ and quantification of EGFP-LC3B dots. Bar $=10 \mu \mathrm{m}$. c Western blot analysis of LC3B-I and LC3B-II in A549 cells treated with compound $\mathbf{5 e}(10 \mu \mathrm{M})$, Baf-A1 $(50 \mathrm{nM})$, or both for $12 \mathrm{~h}$ and quantification of LC3B-II levels. $\mathbf{d}$ Western blot analysis of RPS6KB1 and p-RPS6KB1 (S424/T421) in A549 cells treated with compound $\mathbf{5 e}$ at $10 \mu \mathrm{M}$ for indicated times and quantification. e Western blot analysis of EIF4EBP1 and p-EIF4EBP1 (S65/T70) in A549 cells treated with $\mathbf{5 e}$ at $10 \mu \mathrm{M}$ for indicated times and quantification. $\beta$-actin was used as a loading control. Results were presented as mean $\pm \mathrm{SE} ; n=3 ;{ }^{*} p<0.05 ;{ }^{* *} p<0.01$.

treatment with $5 \mathbf{e}$ enhanced the G1 population by $33.8 \%$ (Fig. S2A). Necrosis, an unwanted side effect of cancerfighting agents, could be evaluated by the LDH assay. LDH assay was performed on cells treated with the compounds and $0.1 \%$ DMSO. Our data revealed that these compounds had no influence on the release of LDH (Fig. S2B).

\section{Compound 5e distributed in lysosome in A549 cells}

Given these compounds containing fluorescent group, we detected the fluorescence in A549 cells by a fluorescent microscope. The data indicated that these compounds have good excellent water-solubility and membrane permeability, especially compound $5 \mathbf{e}$ had good fluorescence at $0.1 \mu \mathrm{M}$ (Fig. S3). Combining with 5e showed good cell growth inhibition activity and high selectivity, this compound was chosen for further mechanism research.

First, the intracellular distribution of compound $5 \mathbf{e}$ in A549 cells was explored according to good fluorescence. We used commercial lysosome probe (Lyso Sensor Green), mitochondria probe (mitochondria Deep Red), and endoplasmic reticulum probe (ER red) to co-stain A549 cells. The result showed that compound 5e had good co-localization with lysosome (Pearson's coefficient 0.903), but poor with mitochondria (Pearson's coefficient 0.563) or endoplasmic reticulum (Pearson's coefficient 0.733) (Fig. 2a), implying a preferential distribution of compound $5 \mathbf{e}$ in lysosome. Furthermore, the concentration of compound $5 \mathbf{e}$ had no significant effect on its cellular distribution (Fig. 2b).

\section{Compound 5e induced autophagy of A549 cells}

Autophagy is a highly conserved lysosomal degradation pathway in which unnecessary byproducts and damaged organelles are engulfed into double-membrane vesicles termed autophagosomes and transported to lysosomes $^{44,45}$. Due to compound 5e located in lysosomes, we investigated the effect of this compound on autophagy. LC3B, an autophagy maker, was monitored by western blotting. The result showed that the levels of LC3B-II were enhanced after incubation with $5 \mathbf{e}$ at $10 \mu \mathrm{M}$ for 3,6 , 12 and $24 \mathrm{~h}$, indicating compound $5 \mathbf{e}$ induced autophagy in a time-dependent manner (Fig. 3a). Moreover, autophagic LC3B-II accumulation was dramatically enhanced in stably expressing EGFP-LCB3 U87 cells in a timedependent manner (Fig. 3b). Actually, all other compounds could also induce autophagy (Fig. S4). In order to demonstrate whether compound 5e could induce intact autophagy flux, Baf-A1, a recognized inhibitor of vacuolar $\mathrm{H}^{+}$-ATPase, was used to block autophagy. As shown in Fig. 3c, treatment with compound 5e further enhanced the accumulation of LC3B-II induced by Baf-A1, implying that compound 5e could induce complete autophagy flux. To assess the impact of autophagic flux in 5e-induced cell death, we analyzed cell viability and cell death by pretreating A549 cells with autophagy inhibitors, chloroquine, and Baf-A1. The results showed that these two inhibitors both could increase the cell viabilities compared with cells treated with 5e solely (Fig. S5A,B). We further confirmed the role of autophagic flux in the action of $\mathbf{5 e}$ by knockdown of specific autophagy-related LC3B gene. Reduction of LC3B by siRNA significantly alleviated cytotoxic activity of 5e (Fig. S5C,D). Taken together, our data clearly demonstrated that $\mathbf{5 e}$ activated an autophagic flux and promoted autophagy-dependent cell death. Compound 5e had no influence on the growth of HUVECs and could not induce autophagy in HUVECs (Fig. S6).

mTOR is a crucial molecular during the process of autophagy. To understand whether compound 5e can suppress the activity of mTOR, we examined the influence of compound 5e on the phosphorylation of RPS6KB1 (ribosomal protein S6 kinase, $70 \mathrm{kDa}$, polypeptide 1) and EIF4EBP1 (eukaryotic translation initiation factor 4Ebinding protein 1), two essential substrates of $\mathrm{mTOR}^{36,37}$. Obviously, the levels of phosphorylation of RPS6KB1 and EIF4EBP1 were significantly decreased after treatment with compound 5e for 3, 6, 12 and $24 \mathrm{~h}$ (Fig. 3d, e). The levels of p-mTOR and mTOR were detected by immunofluorescence staining based on the fluorescence characteristics of compound $5 \mathbf{e}$. The data showed that $\mathbf{5 e}$ could reduce the phosphorylation of mTOR (Fig. S7). Therefore, compound 5e might induce autophagy in an mTOR-dependent manner.

\section{Compound 5e targeted to FKBP12 and inhibited mTOR}

3-Benzyl-5-((2-nitrophenoxy)methyl)-dihydrofuran-2 $(3 \mathrm{H})$-one $(3 \mathrm{BDO})$, which was found by our group, could activate mTOR by targeting FKBP12 (FK506-binding 

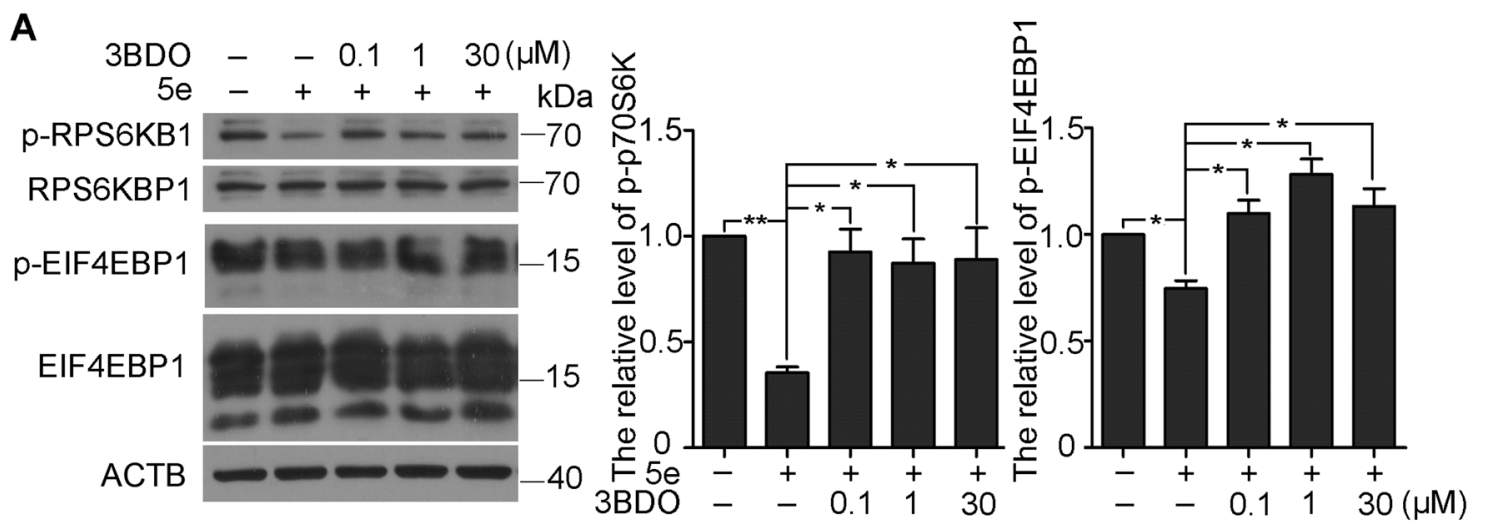

B
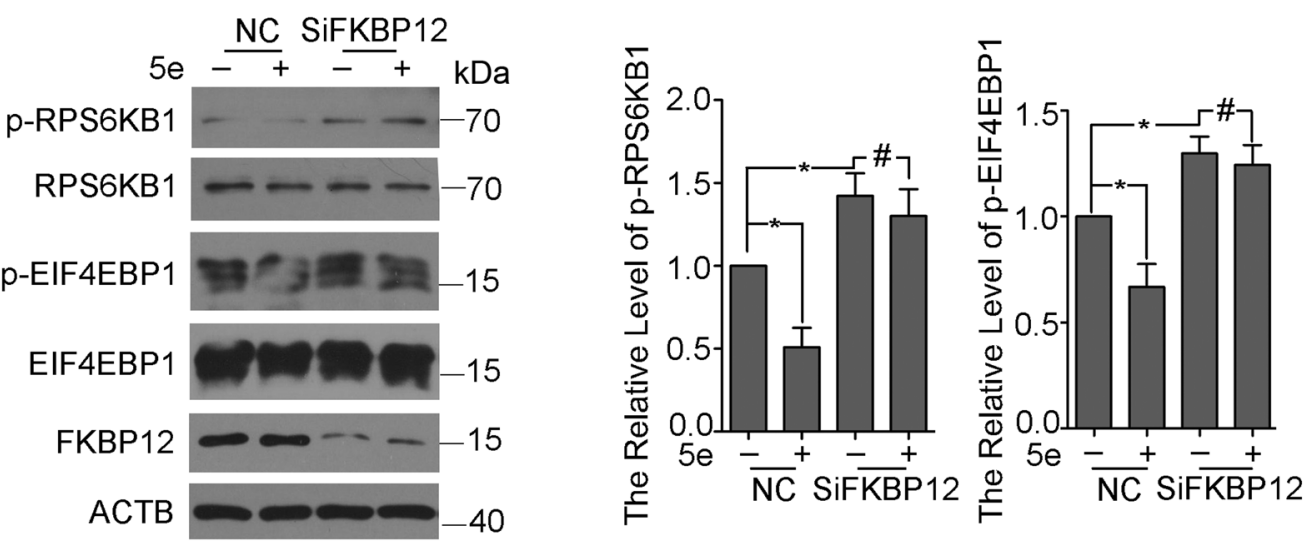

Fig. 4 Compound 5e inhibited mTOR activity via FKBP12. Western blot analysis of RPS6KB1, p-RPS6KB1, EIF4EBP1, and p-EIF4EBP1. a A549 cells were treated with compound $\mathbf{5 e}$ at indicated concentrations for $6 \mathrm{~h}$ along with pretreatment of 3BDO or not. The pretreatment time of $3 \mathrm{BDO}$ was $3 \mathrm{~h}$ and the concentration were $0.1,1$, and $30 \mu \mathrm{M}$ respectively. b A549 cells were treated with compound $\mathbf{5 e}$ for $6 \mathrm{~h}$ in $10 \mu \mathrm{M}$ solely or along with SiFKBP12 in $60 \mathrm{nM}$ for $24 \mathrm{~h}$. $\beta$-actin was used as a loading control. Results were presented as mean $\pm \mathrm{SE} ; n=3 ;{ }^{*} p<0.05 ;{ }^{* *} p<0.01$.

protein $1 \mathrm{~A})^{46}$. To understand how 5e inhibited mTOR, we examined the effect of $5 \mathbf{e}$ on RPS6KB1 and 4EBP1 phosphorylation in the presence or absence of 3BDO. As expected, levels of p-RPS6KB1 and p-EIF4EBP1 were decreased with $5 \mathbf{e}$; however, $5 \mathbf{e}$ failed to decrease the phosphorylation of RPS6KB1 and EIF4EBP1 in the presence of 3BDO (Fig. 4A). Accordingly, the mTOR inhibition of 5e was reversed by 3BDO. Then, SiFKBP12 was used to investigate the molecule target of $5 \mathbf{e}$. The interference efficiency of SiFKBP12 was 56\% in $60 \mathrm{nM}$ (Fig. S8). As shown in Figs. $4 \mathrm{~b}$ and $5 \mathrm{e}$ could not inhibit the activity of mTOR when FKBP12 was knockdown. These results demonstrated that $\mathbf{5 e}$ inhibited the activity of mTOR via FKBP12.

\section{Compound 5e inhibited tumor growth in vivo}

Given compound $5 \mathbf{e}$ effectively inhibited the growth of A549 cell and did not influence the growth of HUVECs in vitro (Fig. 1c), we chose the chick embryo CAM model for further research to evaluate the antitumor effect of $\mathbf{5 e}$. The chick embryo CAM is extensively used for tumor engraftment to evaluate the efficacy of anticancer drugs due to its immune-deficient environment ${ }^{47}$. As shown in Fig. 5a, compared with the DMSO-treated eggs, significant xenograft tumor remission was observed after 6 days in eggs treated with compound 5e. Notably, compound 5e exerted a better antitumor effect than the therapeutic drug 5-Fu. We further detected that compound 5e had no significant toxicity on angiogenesis in vivo in contrast with 5-Fu which suppressed capillary formation (Fig. 5b). Therefore, 5e effectively inhibited tumor growth in vivo without adverse effect on normal CAM angiogenesis.

\section{Compound 5e induced A549 cells autophagy in vivo}

To further investigate the mechanism by which compound 5e inhibited tumor growth in vivo, we prepared frozen sections of solid tumors formed on CAM. Immunofluorescence experiment was performed on frozen sections of tumor. Data showed that compound 5e elevated the level of LC3B-II in tumor tissue, which was in accordance with the results in vitro (Fig. 5c). These data demonstrated that $\mathbf{5 e}$ inhibited lung cancer growth through inducing autophagy in vivo. 
A

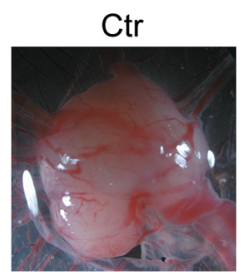

$25 \mu \mathrm{M}$

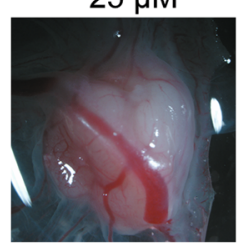

B

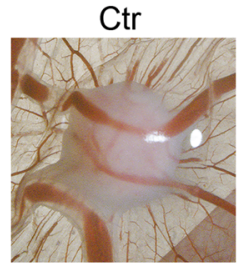

$25 \mu \mathrm{M}$

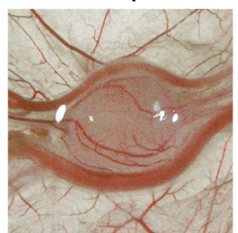

C

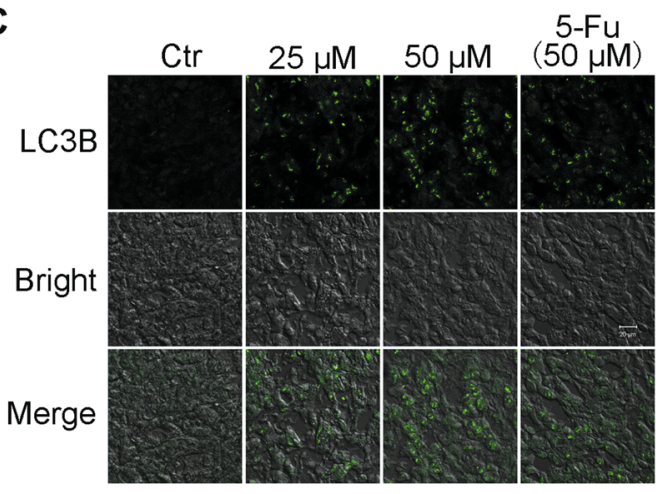

\section{$5-\mathrm{Fu}(50 \mu \mathrm{M})$}
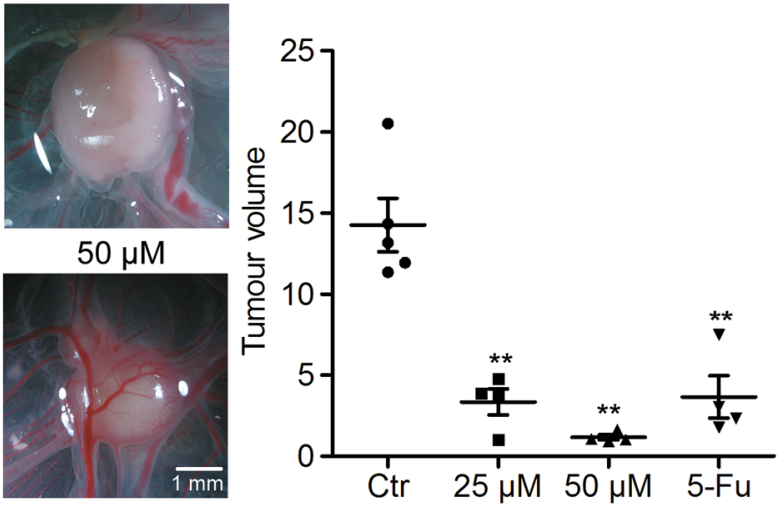

$5-\mathrm{Fu}(50 \mu \mathrm{M})$
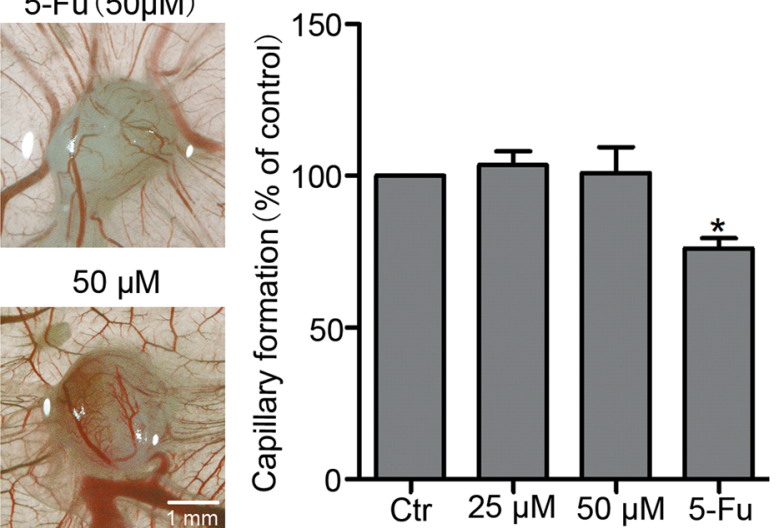

$50 \mu \mathrm{M}$

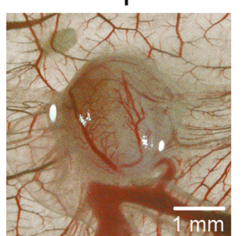

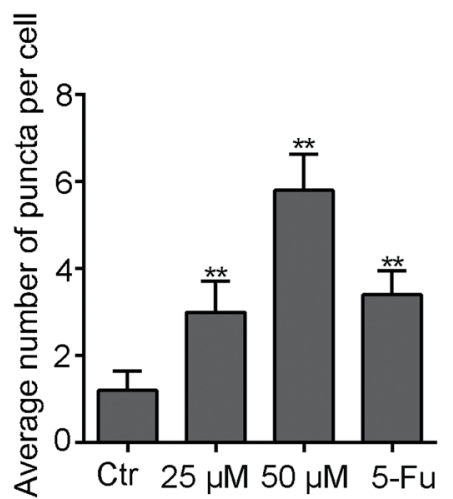

Fig. 5 Compound 5 e inhibited the growth of tumor in vivo. $\mathbf{a}$ Biomicroscopy imaging of control and treated tumors. Bar $=1$ mm. $\mathbf{b}$ Biomicroscopy and quantification of capillary formation with and without compound $\mathbf{5 e}$ and 5 -Fu treatment on gelatin sponge. Bar $=1$ mm. $\mathbf{c}$ Immunofluorescence of LC3B-II in the frozen sections of day 6 experimental tumors. Bar $=20 \mu \mathrm{m}$. Results were presented as mean $\pm \mathrm{SE} ; n=3$; * $p<$ $0.05,{ }^{* *} p<0.01$.

\section{Discussion}

Due to the painful side effects of chemotherapeutic drugs, it is necessary for researchers to improve the selectivity of drugs. Understanding the distribution and target of drugs could be very helpful in improving selectivity. In this study, a series of novel fluorescent compounds were synthesized though sample synthesis steps with high yield. The antiproliferative activity of these compounds against was examined. The results showed that they all showed excellent ability compared with 5-FU. Further SAR analysis showed that the antiproliferative activity of these compounds were mainly affected by aryl group in 5 position of pyrazoline moiety. Further mechanism studied showed that these compounds could arrest cell cycle at the G1 phase and had no influence on cell necrosis.

Using its own fluorescence characteristics, our study found that compound $5 \mathbf{e}$ could selectively accumulate in 


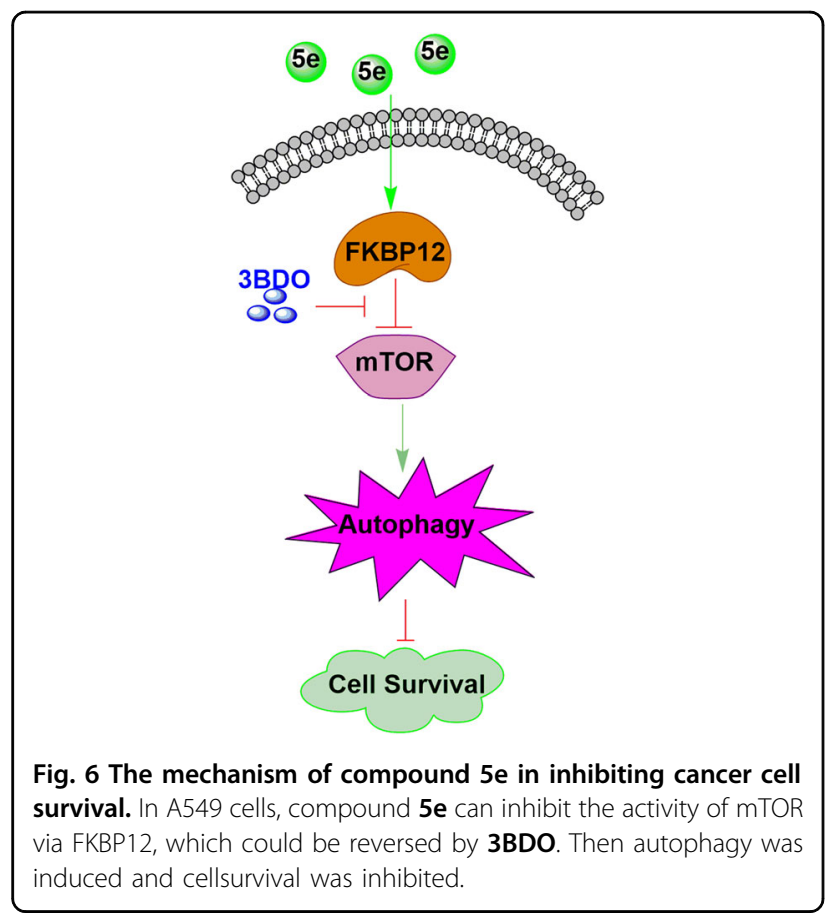

lysosome. Lysosome decomposition is a very important step of autophagy ${ }^{48}$. Autophagy is an indispensable cellular process for protein and organelle quality control. Autophagy is a double-edged sword. Moderate autophagy could promote cell survival, while excessive autophagy could induce cell death ${ }^{28,49}$. Previous studies have indicated that autophagy suppression may be a therapeutic strategy for cancer treatment ${ }^{29,50,51}$. We found that these compounds could induce autophagy and complete autophagy flux.

mTOR has an essential role in different tissues and cells. As mTOR-mediated signaling associated with many diseases, pharmacological agents that modulate mTOR signaling could be helpful in improving many diseases ${ }^{52}$. mTOR also plays an important role in autophagy ${ }^{53}$. In this study, phosphorylation of RPS6KB1 and EIF4EBP1 was significantly decreased by $\mathbf{5 e}$, which could be reversed by 3BDO, an mTOR activator, and autophagy inhibitor. 5e failed to decrease the phosphorylation of RPS6KB1 and EIF4EBP1 when FKBP12 was knockdown. Accordingly, we demonstrated that 5e inhibited mTOR though targeting FKBP12 (Fig. 6). FKBP12 targets mTOR in complex with rapamycin $^{54}$. 3BDO could dock on FKBP12 in the same sites (TYR82A and ILE56A) as rapamycin ${ }^{46}$. The structure of $5 \mathbf{e}$ is different with $3 \mathrm{BDO}$, so we deduced that $5 \mathbf{e}$ might occupy rapamycin binding sites more easily than 3BDO.

CAM model was chosen for further research to evaluate the antitumor effect of $5 \mathbf{e}$ in vivo. Our results showed $\mathbf{5 e}$ significantly inhibited tumor growth compared with 5-FU and showed no adverse influence of angiogenesis.
Immunofluorescence experiment demonstrated that $\mathbf{5 e}$ inhibited lung cancer growth through inducing autophagy in vivo.

In conclusion, we found a series of fluorescent thiazole-pyrazoline derivatives, which could inhibit the growth of A549 cells in vitro and inhibit tumor growth in vivo. Compound 5e induced autophagy though inhibiting the activity of mTOR via FKBP12, which could be reversed by $3 \mathrm{BDO}$, an mTOR activator and autophagy inhibitor. Moreover, compound 5e showed no adverse influence of normal cells and angiogenesis. Therefore, our research provides potential lead compounds for the development of new anticancer drugs against human lung cancer.

\begin{abstract}
Acknowledgements
This work was supported by the National Natural Science Foundation of China (81502948, 31871407, 31741083, and 31870831) and Natural Science Foundation of Shandong Province (2018GSF118201).

\section{Author details}

Institute of Medical Science, The Second Hospital of Shandong University, Jinan 250033, PR China. ${ }^{2}$ Shandong Provincial Key Laboratory of Animal Cells and Developmental Biology, School of Life Science, Shandong University, Jinan 250100, PR China. ${ }^{3}$ Institute of Organic Chemistry, School of Chemistry and Chemical Engineering, Shandong University, Jinan 250100, PR China.

${ }^{4}$ Department of Central Laboratory, Shandong Provincial Hospital affiliated to
\end{abstract} Shandong University, Jinan 250021, PR China

\section{Conflict of interest}

The authors declare that they have no conflict of interest.

\section{Publisher's note}

Springer Nature remains neutral with regard to jurisdictional claims in published maps and institutional affiliations.

Supplementary Information accompanies this paper at (https://doi.org/ 10.1038/s41419-020-02746-W).

Received: 2 December 2019 Revised: 28 June 2020 Accepted: 30 June 2020 Published online: 20 July 2020

\section{References}

1. Torre L. A. et al. Global cancer statistics, 2012. CA- Cancer J. Clin. 65, 87-108 (2015).

2. Hanahan, D. \& Weinberg, R. A. Hallmarks of cancer: the next generation. Cell 144, 646-674 (2011).

3. Keefe, D. M. K. \& Bateman, E. H. Tumor control versus adverse events with targeted anticancer therapies. Nat. Rev. Clin. Oncol. 9, 98-109 (2012).

4. Eisinger, J., Boens, N. \& Flores, J. Fluorescence polarization study of human erythrocyte membranes with 1-phenyl-3-(2-naphthyl)-2-pyrazoline as orientational probe. Biochim. Biophys. Acta 646, 334-343 (1981).

5. Li, M. M., Zhao, W. B. \& Zhang, T. T. A new thiophenyl pyrazoline fluorescent probe for $\mathrm{Cu}^{2+}$ in aqueous solution and imaging in live cell. J. Fluoresc. 23, 1263-1269 (2013).

6. Ahmed, M., Hameed, S., Ihsan, A. \& Naseer, M. M. Fluorescent thiazolsubstituted pyrazoline nanoparticles for sensitive and highly selective sensing of explosive 2,4,6-trinitrophenol in aqueous medium. Sens. Actuat. B-Chem. 248, 57-62 (2017).

7. Bozkurt, E. \& Gul, H. I. A novel pyrazoline-based fluorometric "turn-off" sensing for $\mathrm{Hg}^{2+}$. Sens. Actuat. B-Chem. 255, 814-825 (2018).

8. Xia S. et al. A novel sensitive fluorescent turn-on probe for rapid detection of $\mathrm{Al}^{3+}$ and bioimaging. RSC Adv. 5, 5244-5249 (2015). 
9. Wang L. et al. A novel pyrazoline-based fluorescent probe for detection of hydrazine in aqueous solution and gas state and its imaging in living cells. Sens. Actuat. B-Chem. 229, 441-452 (2016).

10. Zheng X. X. et al. Novel pyrazoline-based selective fluorescent probe for the detection of hydrazine. Spectrochim. Acta A Mol. Biomol. Spectrosc. 138, 247-251 (2015)

11. Zhang R. R. et al. Novel pyrazoline-based fluorescent probe for detecting thiols and its application in cells. Spectrochim. Acta A Mol. Biomol. Spectrosc. 137, 450-455 (2015).

12. Wang S. Q. et al. Novel pyrazoline-based fluorescent probe for detecting glutathione and its application in cells. Biosens. Bioelectron. 55, 386-390 (2014).

13. Tan J. L. et al. A novel "off-on" colorimetric and fluorescent rhodamine-based $\mathrm{pH}$ chemosensor for extreme acidity. Spectrochim. Acta A Mol. Biomol. Spectrosc. 140, 489-494 (2015)

14. Li, J., Li, D., Han, Y., Shuang, S. \& Dong, C. Synthesis of 1-phenyl-3-biphenyl-5(N-ethylcarbazole-3-yl)-2-pyrazoline and its use as DNA probe. Spectrochim. Acta A Mol. Biomol. Spectrosc. 73, 221-225 (2009).

15. Silver, K. S. \& Soderlund, D. M. Differential sensitivity of rat voltage-sensitive sodium channel isoforms to pyrazoline-type insecticides. Toxicol. Appl. Pharmacol. 214, 209-217 (2006).

16. Zhao P. L. et al. Synthesis, fungicidal, and insecticidal activities of betamethoxyacrylate-containing $\mathrm{N}$-acetyl pyrazoline derivatives. J. Agric. Food Chem. 56, 10767-10773 (2008).

17. Silver, K. \& Soderlund, D. M. State-dependent block of rat Nav1.4 sodium channels expressed in xenopus oocytes by pyrazoline-type insecticides. Neurotoxicology 26, 397-406 (2005).

18. Mishra, N. \& Sasmal, D. Development of selective and reversible pyrazoline based MAO-B inhibitors: virtual screening, synthesis and biological evaluation. Bioorg. Med. Chem. Lett. 21, 1969-1973 (2011).

19. Chimenti F. et al. Synthesis and inhibitory activity against human monoamine oxidase of N1-thiocarbamoyl-3,5-di(hetero)aryl-4,5-dihydro-(1H)-pyrazole derivatives. Eur. J. Med. Chem. 45, 800-804 (2010).

20. Rathish I. G. et al. Synthesis and antiinflammatory activity of some new 1,3,5trisubstituted pyrazolines bearing benzene sulfonamide. Bioorg. Med. Chem. Lett. 19, 255-258 (2009).

21. Chirumarry S. et al. Design, synthesis and surfactant properties of perfluorobutyl-based fluorinated sodium alkanesulfonates. J. Fluor. Chem. 197, 111-117 (2017)

22. Sharma P. K. et al. Synthesis and biological evaluation of some pyrazolylpyrazolines as anti-inflammatory-antimicrobial agents. Eur. J. Med. Chem. 45 2650-2655 (2010)

23. Hu L. et al. Synthesis and antibacterial activity of C-12 pyrazolinyl spiro ketolides. Eur. J. Med. Chem. 45, 5943-5949 (2010).

24. Siddiqui, Z. N., Musthafa, T. N., Ahmad, A. \& Khan, A. U. Thermal solvent-free synthesis of novel pyrazolyl chalcones and pyrazolines as potential antimicrobial agents. Bioorg. Med. Chem. Lett. 21, 2860-2865 (2011).

25. Marella A. et al. Pyrazolines: a biological review. Mini-Rev. Med. Chem. 13, 921-931 (2013).

26. Altintop M. D. et al. A novel series of thiazolyl-pyrazoline derivatives: synthesis and evaluation of antifungal activity, cytotoxicity and genotoxicity. Eur. J. Med. Chem. 92, 342-352 (2015).

27. Yang W. et al. Design, modification and 3D QSAR studies of novel naphthalincontaining pyrazoline derivatives with/without thiourea skeleton as anticancer agents. Bioorg. Med. Chem. 21, 1050-1063 (2013).

28. Mizushima, N. \& Komatsu, M. Autophagy: renovation of cells and tissues. Cell 147, 728-741 (2011)

29. Fulda, S. \& Kogel, D. Cell death by autophagy: emerging molecular mechanisms and implications for cancer therapy. Oncogene 34,5105-5113 (2015).
30. Mulcahy Levy, J. M., Towers, C. G. \& Thorburn, A. Targeting autophagy in cancer. Nat. Rev. Cancer 17, 528-542 (2017).

31. Galluzzi, L., Bravo-San Pedro, J. M., Levine, B., Green, D. R. \& Kroemer, G. Pharmacological modulation of autophagy: therapeutic potential and persisting obstacles. Nat. Rev. Drug Discov. 16, 487-511 (2017).

32. Amaravadi R. K. et al. Principles and current strategies for targeting autophagy for cancer treatment. Clin. Cancer Res. 17, 654-666 (2011).

33. Kondo, Y. \& Kondo, S. Autophagy and cancer therapy. Autophagy 2, 85-90 (2006).

34. Laplante, M. \& Sabatini, D. M. mTOR signaling in growth control and disease. Cell 149, 274-293 (2012).

35. Weichhart, T. Mammalian target of rapamycin: a signaling kinase for every aspect of cellular life. Methods Mol. Biol. 821, 1-14 (2012).

36. Mamane $\mathrm{Y}$. et al. mTOR, translation initiation and cancer. Oncogene $\mathbf{2 5}$ 6416-6422 (2006)

37. Zaytseva, Y. Y., Valentino, J. D., Gulhati, P. \& Evers, B. M. mTOR inhibitors in cancer therapy. Cancer Lett. 319, 1-7 (2012).

38. Alayev, A. \& Holz, M. K. mTOR signaling for biological control and cancer. J. Cell Physiol. 228, 1658-1664 (2013).

39. Zhang, J. F., Li, M., Miao, J. Y. \& Zhao, B. X. Biological activities of novel pyrazolyl hydroxamic acid derivatives against human lung cancer cell line A549. Eur. J. Med. Chem. 83, 516-525 (2014).

40. Wei Q. et al. Discovery of novel HSP90 inhibitors that induced apoptosis and impaired autophagic flux in A549 lung cancer cells. Eur. J. Med. Chem. 145, 551-558 (2018)

41. Li N. et al. Discovery of a new autophagy inducer for A549 lung cancer cells. Bioorg. Med. Chem. 27, 2845-2856 (2019).

42. Papazisis, K. T., Geromichalos, G. D., Dimitriadis, K. A. \& Kortsaris, A. H. Optimization of the sulforhodamine B colorimetric assay. J. Immunol. Methods $\mathbf{2 0 8}$ 151-158 (1997).

43. Zhang X. et al. New fluorescent $\mathrm{pH}$ probes for acid conditions. Sens. Actuat. BChem. 206, 663-670 (2015).

44. Jaishy, B. \& Abel, E. D. Lipids, lysosomes, and autophagy. J. Lipid Res. 57 1619-1635 (2016).

45. Settembre $C$ et al. A lysosome-to-nucleus signalling mechanism senses and regulates the lysosome via mTOR and TFEB. EMBO J. 31, 1095-1108 (2012).

46. Ge D. et al. Identification of a novel MTOR activator and discovery of a competing endogenous RNA regulating autophagy in vascular endothelial cells. Autophagy 10, 957-971 (2006).

47. Lokman, N. A., Elder, A. S. F., Ricciardelli, C. \& Oehler, M. K. Chick chorioallantoic membrane (CAM) assay as an in vivo model to study the effect of newly identified molecules on ovarian cancer invasion and metastasis. Int. J. Mol. Sci. 13, 9959-9970 (2012)

48. Settembre, C., Fraldi, A., Medina, D. L. \& Ballabio, A. Signals from the lysosome: a control centre for cellular clearance and energy metabolism. Nat. Rev. Mol. Cell Biol. 14, 283-296 (2013).

49. Rabinowitz, J. D. \& White, E. Autophagy and metabolism. Science $\mathbf{3 3 0}$ 1344-1348 (2010)

50. Liu R. et al. Itraconazole suppresses the growth of glioblastoma through induction of autophagy: 8 involvement of abnormal cholesterol trafficking. Autophagy 10, 1241-1255 (2014)

51. Nassour J. et al. Autophagic cell death restricts chromosomal instability during replicative crisis. Nature 565, 659-663 (2019).

52. Zoncu, R., Efeyan, A. \& Sabatini, D. M. mTOR: from growth signal integration to cancer, diabetes and ageing. Nat. Rev. Mol. Cell Biol. 12, 21-35 (2011).

53. Yu L. et al. Termination of autophagy and reformation of lysosomes regulated by mTOR. Nature 465, 942-946 (2010).

54. Huang, S., Bjornsti, M. A. \& Houghton, P. J. Rapamycins: mechanism of action and cellular resistance. Cancer Biol. Ther. 2, 222-232 (2003). 